\title{
High-Power Wavelength Bistability and Tunability in Passively Mode-Locked Quantum-Dot Laser
}

\author{
Daniil I. Nikitichev, Member, IEEE, Maria A. Cataluna, Member, IEEE, Ksenia A. Fedorova, Member, \\ IEEE, Ying Ding, Member, IEEE, Sergey S. Mikhrin, Igor L. Krestnikov, Daniil A. Livshits, Edik U. \\ Rafailov, Senior Member, IEEE
}

\begin{abstract}
Wavelength bistability and tunability are demonstrated in a two-section quantum-dot mode-locked laser with a non-identical capping layer structure. The continuous wave output power of $30 \mathrm{~mW}(25 \mathrm{~mW})$ and mode-locked average power of $27 \mathrm{~mW}(20 \mathrm{~mW})$ are achieved for $1245 \mathrm{~nm}(1295 \mathrm{~nm})$ wavelengths respectively under the injection current of $300 \mathrm{~mA}$. The largest switching range of more than $50 \mathrm{~nm}$ and wavelength tuning range with picosecond pulses and stable lasing wavelengths between $1245 \mathrm{~nm}$ and $1295 \mathrm{~nm}$ are demonstrated for gain current of $300 \mathrm{~mA}$ and $330 \mathrm{~mA}$.
\end{abstract}

Index Terms - Laser mode-locking, quantum dot lasers, optical pulses, laser tuning, wavelength bistability.

\section{INTRODUCTION}

First work on optical bistability associated with two stable optical output states in semiconductors laser was published more than 4 decades ago when Lasher proposed using bistable semiconductor laser as functional device [1]. Wavelength bistability of semiconductors lasers is still interesting and excited area for future development of the next generation optical communication systems [2]. Due to unique structural, electronic and optical properties of quantum-dots lasers such as low threshold current density, ultrafast carrier dynamics, low temperature sensitivity, broad gain bandwidth, delta-function peak

Manuscript received October 12, 2012. This work was supported by the European Community's Seventh Framework Programme (FP7/20072013) under grant agreement $n^{\circ} 224338$ (FAST-DOT project). M. A. Cataluna also acknowledges financial support through a Royal Academy of Engineering/EPSRC Research Fellowship.

D. I. Nikitichev, K. A. Fedorova, E. U. Rafailov are with the Photonics and Nanoscience Group, School of Engineering, Physics and Mathematics, University of Dundee, Dundee DD1 4HN, U. K.

(e-mail: d.nikitichev@dundee.ac.uk, k.a.fedorova@dundee.ac.uk, e.u.rafailov@dundee.ac.uk).

M. A. Cataluna and Y. Ding were with the Photonics and Nanoscience Group and are currently with the Ultrafast Photonics Group, School of Engineering, Physics and Mathematics, University of Dundee, Dundee DD1 4HN, U. K.

(e-mail: m.a.cataluna@dundee.ac.uk, y.ding@dundee.ac.uk).

S. S. Mikhrin, I. L. Krestnikov, D. A. Livshits are with Innolume $\mathrm{GmbH}$, Germany, Konrad-Adenauer-Allee 11, 44263, Dortmund, Germany

(email:semi@innolume.com,

DaLi@innolume.com). density of states, they have shown great potential as cost efficient, compact, low noise and high repetition rate optical devices [3].

Among other advantages quantum-dot mode-locked lasers demonstrated switching regimes between ground state and excited states separately controlled by driving conditions of gain and absorber [3-9]. It does open new doors for the development of multi-wavelength ultrafast devices for nonlinear frequency conversion, flip-flop memory switches, dual-wavelength microscopy modalities (CARS, STED), time-domain spectroscopy and wavelengthdivision multiplexing [9-12]. Continuous-wave (CW) bistability in the light-current (L-I) characteristics and self-pulsation in quantum-dot lasers may occur with increase current to the gain section and explained by nonlinear saturation of the quantum-dot absorption and electroabsorption induced by the quantum confined Stark effect [13-14]. Wavelength bistability was observed in distributed feedback laser in continuous-wave (CW) [15] as well as in vertical-cavity semiconductor optical amplifiers [16]. Wavelength bistability in mode-locked lasers was demonstrated for different laser structures [1718].

Furthermore, QD growth technologies have now matured to a level which enables a high degree of control over the emission spectrum of QD devices, which can be tailored and significantly broadened for different applications, such as broadly-tunable laser [19, 20]. For instance, QD external-cavity diode lasers incorporating multiple chirped QD layers have demonstrated impressive tuning range of more than $200 \mathrm{~nm}$ with nearly $0.5 \mathrm{~W}$ maximum output power [19]. On the other hand, the broad bandwidth available from these QD gain media has also been exploited in monolithic multi-section devices, which have shown the possibility of a continuous sweeping region between $1029.1 \mathrm{~nm}$ to $1017.4 \mathrm{~nm}(11.7 \mathrm{~nm})$ and also extending to $1004.3 \mathrm{~nm}$ (with a total $24.8 \mathrm{~nm}$ sweep range), by applying different injection currents to the multiple sections [20]. Moreover, different substrate materials were investigated.

Recently we reported wavelength bistability of the two section quantum dot (QD) mode-locked laser with $\mathrm{CW}$ output power of $25 \mathrm{~mW}$ and mode-locked average power of $17 \mathrm{~mW}$ [21] which is one to two orders of 
magnitude higher than previous results [17-18] and best to our knowledge switching range. In this paper we demonstrate further investigation of wavelength bistability for higher gain current and present electronically-controlled $45 \mathrm{~nm}$ tunability range from the same device, allowing for the generation of picosecond pulses electronically tunable between $1245 \mathrm{~nm}$ and 1290 $\mathrm{nm}$, with a pulse repetition rate of around $10 \mathrm{GHz}$. This represents a completely new regime of operation of modelocked laser diodes, which significantly enhances their spectral versatility, while offering the potential for highspeed electronic tuning.

\section{EXPERIMENTAL SeTUP}

The investigated multi-section laser had a ridge waveguide width of $6 \mu \mathrm{m}$ and a total length of $4 \mathrm{~mm}$, resulted in a pulse repetition rate of $10 \mathrm{GHz}$ when modelocked, as defined by the cavity round-trip time. The device consisted of multiple 1-mm-long electricallyinsulated sections; each of these further divided into $300 \mu \mathrm{m}$ and $700 \mu \mathrm{m}$ sub-sections as shown in Fig.1.

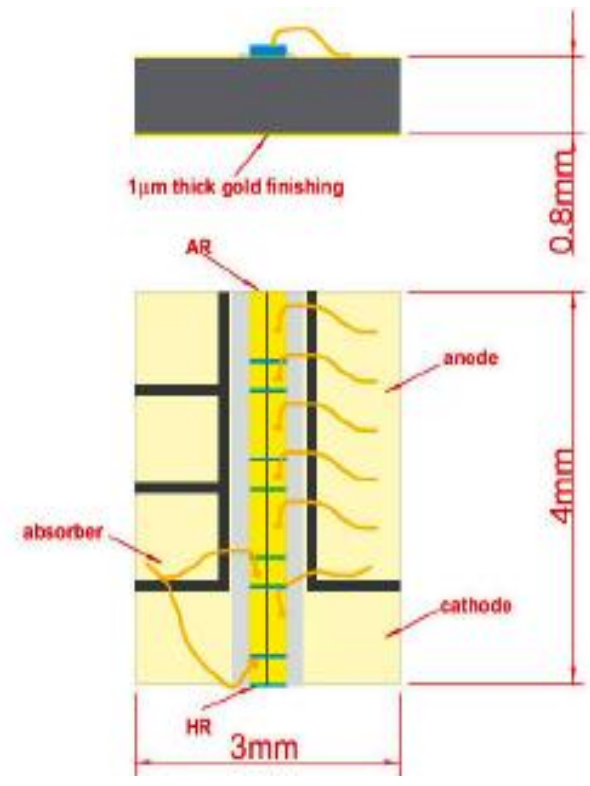

Fig. 1 The geometry of the $4 \mathrm{~mm}$ long device divided in $300 \mu \mathrm{m}$ and 700 $\mu \mathrm{m}$. Last two $300 \mu \mathrm{m}$ sections placed nearer the back facet forms a saturable absorber.

A reverse bias was applied to the two $300 \mu \mathrm{m}$ sections placed nearer the back facet, thus forming a distributed saturable absorber with a total length of $600 \mu \mathrm{m}$. The gain section was formed by the remaining sections which were forward biased. The output facet was deep-anti-reflection coated (on the gain section side), while the back facet was high-reflection coated (on the absorber side), with reflectivities of approximately $0.1 \%$ and 95\%, respectively. The QD structure was grown on a GaAs substrate by molecular beam epitaxy. Its active region consisted of 10 InAs QD layers covered by non-identical InGaAs capping layers, incorporated into $\mathrm{Al}_{0.35} \mathrm{Ga}_{0.65} \mathrm{As}$ cladding layers. The size of the QDs is related to the wavelength emission and can be control to some extent by manipulating the thickness of capping layers which leads to variance of the indium segregation into the QDs. As a result, the larger size of QDs leads to the longer emission wavelength. This structure consisted of 3 QD layers with an emission spectrum centered approximately at $1211 \mathrm{~nm}$, 3 QD layers at $1243 \mathrm{~nm}$ and finally $4 \mathrm{QD}$ layers at $1285 \mathrm{~nm}$ (see Fig. 2). The higher number of layers for larger QDs was used to keep the gain spectrum relatively flat as the density of dots is decreased with the increasing QD size as explained in ref. [19]. As the QD laser operates at longest wavelengths the threshold current is low and comparable with the identical layers QD laser but increases for shorter wavelengths operation due to the parasitic contribution from the larger size QDs. The laser was kept at $20^{\circ} \mathrm{C}$ by a Peltier cooler. The gain section was pumped with a low-noise current source and the absorber section was connected to a voltage source. The pulse durations were measured by a non-collinear autocorrelator based on second-harmonic generation. The spectral characteristics were measured by a spectrometer, assuming the central wavelength as the highest peak after fitting the Gaussian shape. The mode-locking performance was further investigated with an RF spectrum analyzer in combination with a high-speed $29 \mathrm{GHz}$ photodiode.

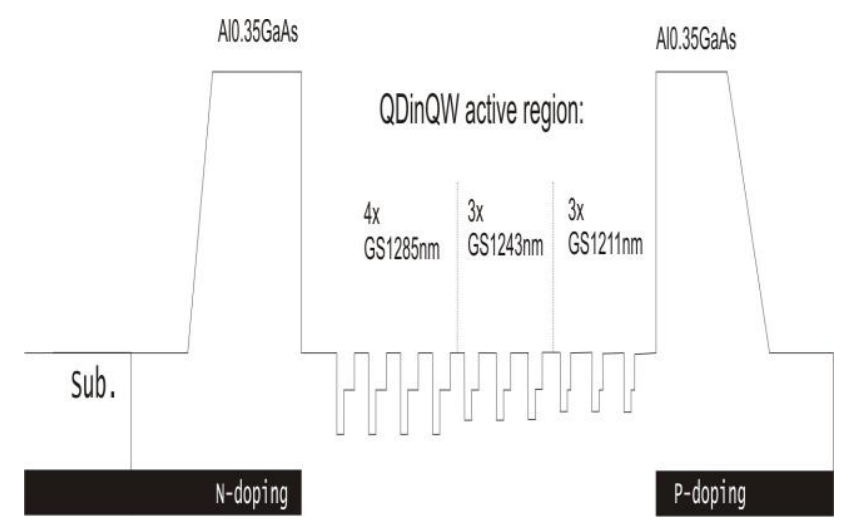

Fig. 2 The layers structure of the mode-locked quantum dot laser consisting of $10 \mathrm{InAs}$ QD layers covered by non-identical InGaAs capping layers, incorporated into $\mathrm{Al} 0.35 \mathrm{Ga} 0.65 \mathrm{As}$ cladding layers.

\section{Wavelength Bistability and Tunability}

Mode-locking region mapping for this device is presented in Fig. 3. As it can be seen, dual ground state 
continuous wave (GSCW) regime was observed for gain current above $300 \mathrm{~mA}$ as shown in Fig. 3 (light grey region) which originates from non-linear gain saturation at the ground state and the redistribution of free carriers at higher order lasing modes [9]. The ground state modelocking (GSML) occurs for reverse bias between $3 \mathrm{~V}$ and $11 \mathrm{~V}$ and gain current from $200 \mathrm{~mA}$ up to $550 \mathrm{~mA}$. The two particular regions were observed in GSML regime of operation: wavelength bistability (red circle in Fig. 3) and wavelength tunablity (blue circle in Fig. 3). The experimental results for fixed gain currents of $300 \mathrm{~mA}$ and $330 \mathrm{~mA}$ with different reverse bias were examined in more details as under such driving conditions both wavelength bistability and wavelength tunability occur.

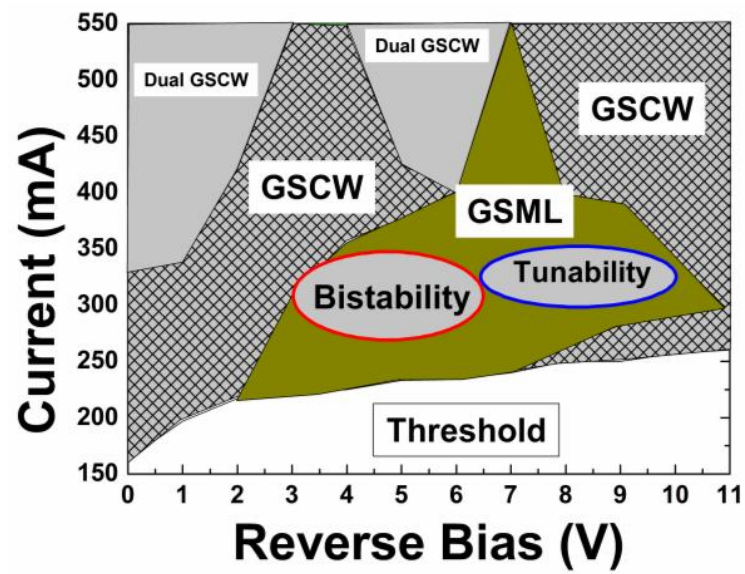

Fig. 3.Mapping of mode-locking region: Dual GSCW- coexistence of dual ground state continuous wave emissions, GSCW - ground state continuous wave transition, GSML - ground state mode-locking region with wavelength bistability (red circle) and wavelength tunability (blue circle) regions highlighted.

The wavelength bistability for fixed gain current of 260 $\mathrm{mA}$ was observed between $\sim 1295 \mathrm{~nm}$ and $\sim 1245 \mathrm{~nm}$ for $2.5 \mathrm{~V}$ and $7.5 \mathrm{~V}$ applied voltage to reverse bias, it is similar what was presented in ref. 21. The wavelength bistability in mode-locked regime in this device can be observed in a wider range of currents between $260 \mathrm{~mA}$ and $330 \mathrm{~mA}$ compared to a few $\mathrm{mA}$ region achieved previously [17-18, 21] (see Fig. 3 red circle). It indicates that bistability is more stable, reproducible and reliable. For fixed current of $300 \mathrm{~mA}$ and $330 \mathrm{~mA}$ applied to the gain section, we observed two regimes of operation. For low values of reverse bias, more than $50 \mathrm{~nm}$ wavelength switching regime (between $\sim 3 \mathrm{~V}$ and $\sim 7 \mathrm{~V}$ of reverse bias) was observed, which is the widest to our knowledge. For higher values of reverse bias from $7 \mathrm{~V}$ to $11 \mathrm{~V}-$ the wavelength tuning regime is observed as shown in Fig. 4. Hysteresis, wavelength bistability and tunability are shown in Fig. 4 (a) for gain current of $300 \mathrm{~mA}$. It shows dependence on the direction of the applied voltage in the region of $1-5 \mathrm{~V}$. When we applied voltage from $0-7 \mathrm{~V}$ (black curve), we observed that the laser was lasing at $\sim 1295 \mathrm{~nm}$ in continuous wave from 0 to $3 \mathrm{~V}$, then modelocking started at the same wavelength till the voltage reached $5 \mathrm{~V}$. At that point the wavelength abruptly was switched to $\sim 1245 \mathrm{~nm}$. The mode-locking at that wavelength was observed until $7 \mathrm{~V}$. As reverse bias applied higher than $7 \mathrm{~V}$ the wavelength gradually increases up to $1290 \mathrm{~nm}$ in mode-locked regime. In the opposite direction (red curve) the wavelength decreases from $1290 \mathrm{~nm}$ to $1245 \mathrm{~nm}$ with decrease of the applied voltage up to $7 \mathrm{~V}$ and then mode-locking regime was observed only at $\sim 1245 \mathrm{~nm}$ up to $3 \mathrm{~V}$ (Fig. 4 (a)). Then the laser stopped to operate in the mode-locking regime and worked in the continuous-wave regime. A dual GSCW regime was observed around $1 \mathrm{~V}$ in the descending direction of applied voltage to the absorber. The origin of this operation regime can be attributed to the saturation effect of the $\sim 1250 \mathrm{~nm}$ lasing wavelength and the redistribution of the increased number of free carriers as reverse bias decreased. The widest spectral separation about $52 \mathrm{~nm}$ was obtained between $1299 \mathrm{~nm}$ and $1247 \mathrm{~nm}$ at $3.8 \mathrm{~V}$ reverse bias. The tuning spectral range of $\sim 45 \mathrm{~nm}$ in mode-locked regime was achieved between $\sim 1250 \mathrm{~nm}$ and $\sim 1290 \mathrm{~nm}$ for high reverse bias $(7 \mathrm{~V}-11 \mathrm{~V})$.
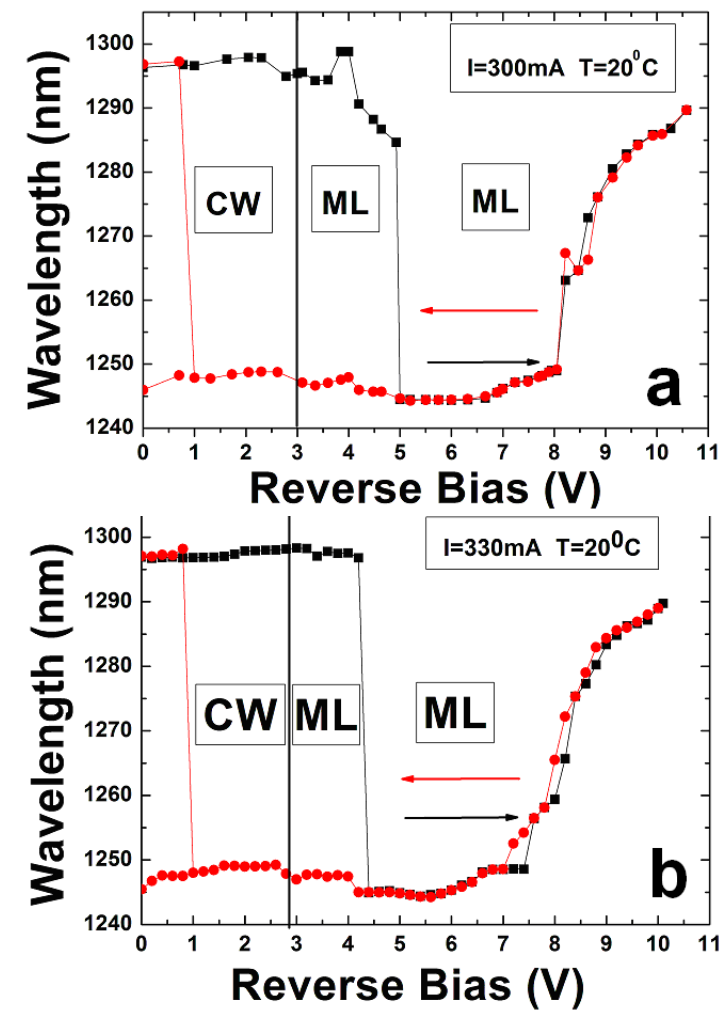

Fig. 4. Dynamics of emission wavelength with various values of ascending (black color) and descending (red color) reverse bias for 300 $\mathrm{mA}$ (a) and $330 \mathrm{ma}$ (b) gain current. Wavelength bistability occurs for continuous wave $(\mathrm{CW})$ in the range of $0-3 \mathrm{~V}$ and mode-locking (ML) regime in the range of $3 \mathrm{~V}-7 \mathrm{~V}$, while wavelength tunability modelocking regime is observed for reverse bias between $7 \mathrm{~V}$ and $11 \mathrm{~V}$ for $300 \mathrm{~mA}$ (a) gain current and $7 \mathrm{~V}$ and $10 \mathrm{~V}$ for $330 \mathrm{~mA}$ gain current (b). 
For fixed gain current of $330 \mathrm{~mA}$ we observed similar switching regime between reverse bias $1 \mathrm{~V}$ and $4.5 \mathrm{~V}$ with the widest switching range of $51.8 \mathrm{~nm}$ at $4.2 \mathrm{~V}$ reverse bias between $1296.8 \mathrm{~nm}$ and $1245 \mathrm{~nm}$ (Fig. 4 (b)). Comparing the wavelength dynamics with reverse bias for gain currents $300 \mathrm{~mA}$ and $330 \mathrm{~mA}$, it can be seen that switching regime is almost the same while for high reverse bias regime wavelength for $330 \mathrm{~mA}$ changes more gradually. Wavelength tunability between $1245 \mathrm{~nm}$ and $1290 \mathrm{~nm}$ for high reverse bias was observed, with the amplitude difference between lasing and non-lasing cavity modes (side-mode suppression ratio) higher than $40 \mathrm{~dB}$ (Fig. 5). It suggests the effectiveness of using novel material QD growth for building tunable electrically controlled optical source.

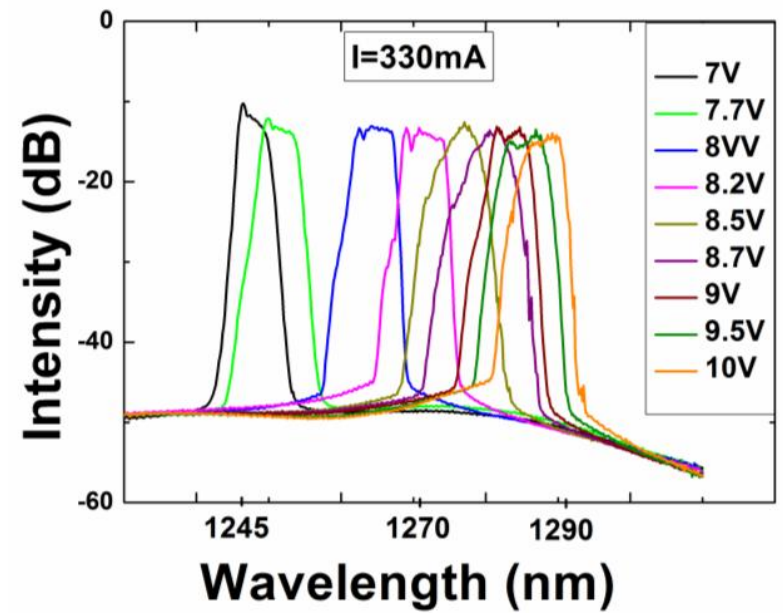

Fig. 5 Spectral tunability with high suppression ratio more than $40 \mathrm{~dB}$ in descending direction for fixed current of $330 \mathrm{~mA}$.

We did observe noticeable discrimination in the L-I characteristics for $300 \mathrm{~mA}$ and $330 \mathrm{~mA}$ as in Ref. [17-18] with the output power level more than $20 \mathrm{~mW}$ compared to $1 \mathrm{~mW}$ which was achieved by Feng et.al. (Fig. 6). The hysteresis loop is explained by nonlinear behavior of the absorber. The absorption inside the absorber decreases nonlinearly as the light power output of the absorber is increased which originates from emptying of the QD ground state transition as explained in Ref. 22. As the result the output power suddenly increases or decreases during backward and forward voltage sweep. The average power reduces with increased reverse bias voltages due to electroabsorption. The highest output powers measured for $300 \mathrm{~mA}$ fixed current were $30.4 \mathrm{~mW}(25.7 \mathrm{~mW})$ and $27 \mathrm{~mW}(20.7 \mathrm{~mW})$ for $\mathrm{CW}$ and mode-locking regimes at $1245 \mathrm{~nm}(1295 \mathrm{~nm})$ respectively. While for injected current of $330 \mathrm{~mA}$ the highest output powers were 29.7 $\mathrm{mW}(24.7 \mathrm{~mW})$ and $27.5 \mathrm{~mW}(20.9 \mathrm{~mW})$ for $\mathrm{CW}$ and mode-locking regimes at $1245 \mathrm{~nm} \quad(1295 \mathrm{~nm})$, respectively. The sudden decrease of the power around $1 \mathrm{~V}$ is due to dual GSCW regime. As the voltage applied in the descending direction the output power increases up to $\sim 30 \mathrm{~mW}$ and in the regime of dual GSCW the power is split equally in both wavelength band $\sim 1250 \mathrm{~nm}$ and $\sim 1295 \mathrm{~nm}$.
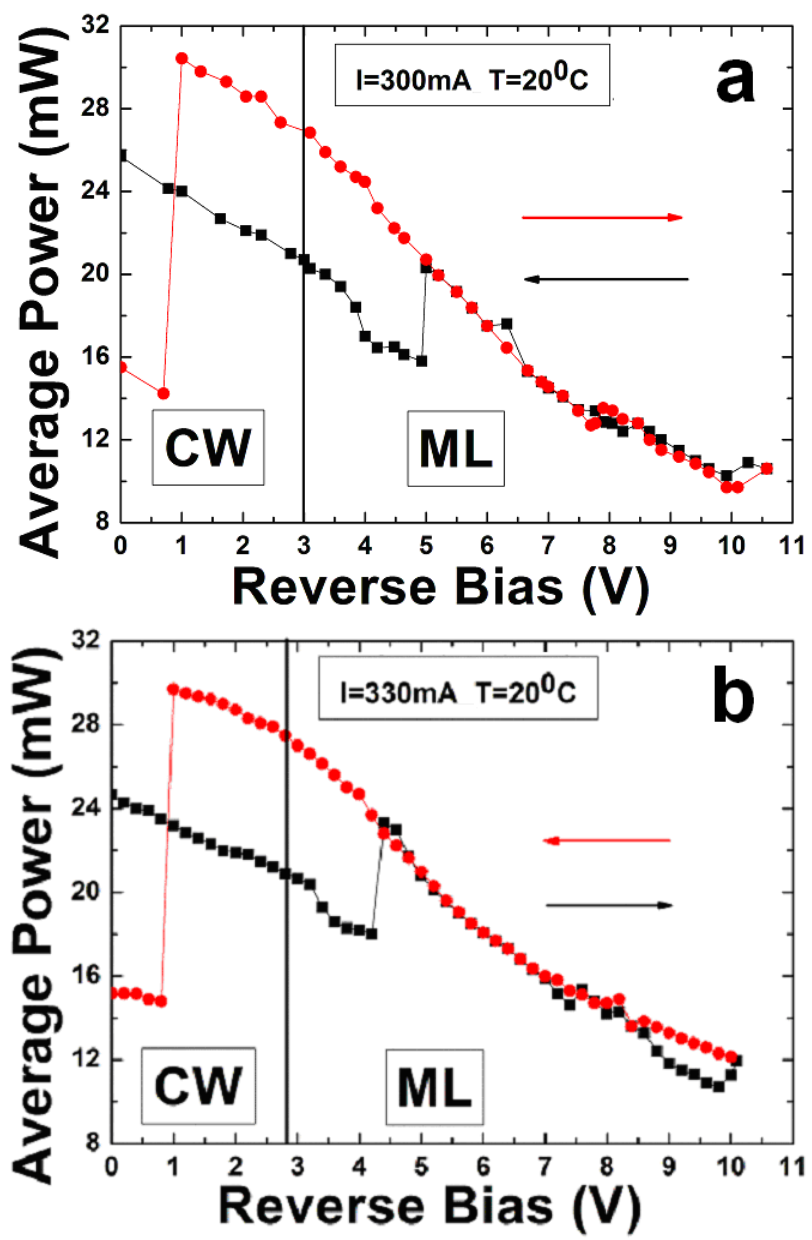

Fig. 6 Output power dependence on reverse bias of absorber for $300 \mathrm{~mA}$ (a) and $330 \mathrm{~mA}$ (b) gain current.

Pulse duration dependence with applied voltage to absorption section changing from $3 \mathrm{~V}$ to $11 \mathrm{~V}$ for fixed gain currents of $300 \mathrm{~mA}$ is shown in Fig. 7. Pulse duration in the mode-locked regime for $300 \mathrm{~mA}$ current changes from $23.2 \mathrm{ps}$ ( $28 \mathrm{ps}$ ) to $3 \mathrm{ps}$ in ascending (descending) directions, respectively. Exponential decrease of the pulse durations with increase of the absorber bias was observed due to exponential decrease of the absorber recovery time [23]. As it becomes shorter the time period over which the pulses experience the gain reduces resulting in shorter pulse duration.

As an example, autocorrelation trace for $7 \mathrm{~V}$ reverse bias and $300 \mathrm{~mA}$ gain current is presented in the inset of Fig. 7. Gaussian shapes have been assumed to calculate the pulse width. The combination of a pulse duration of $3.3 \mathrm{ps}$, and an optical spectrum full-width at half- 
maximum of $4.8 \mathrm{~nm}$ results in a time-bandwidth product (TBWP) of 3.2.

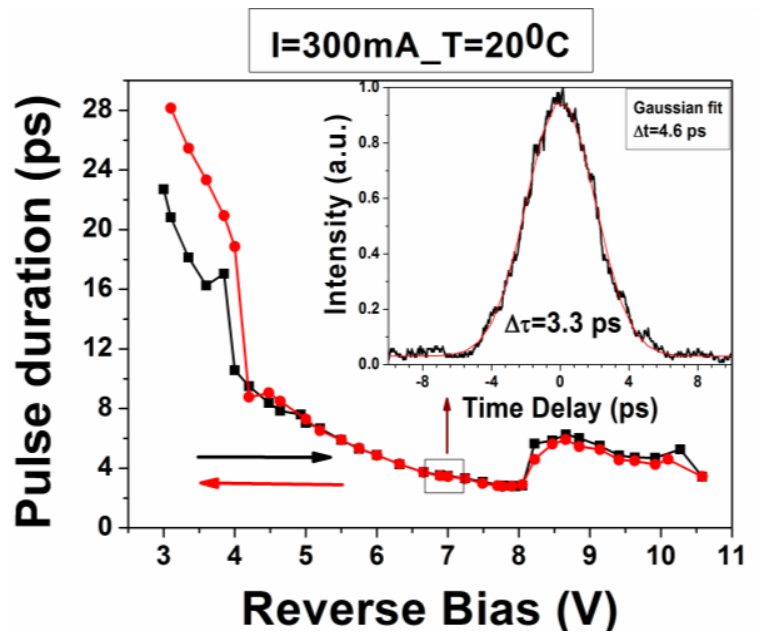

Fig. 7 Pulse width dependence on reverse bias of absorber for $300 \mathrm{~mA}$ gain current. Inset: autocorrelation trace for reverse bias $7 \mathrm{~V}$ corresponding to $3.3 \mathrm{ps}$ pulse width using Gaussian fitting.

As evidence of this tuning regime (high reverse bias) for $300 \mathrm{~mA}$ fixed current in the ascending direction, corresponding optical spectra are depicted in Fig. 8 along with autocorrelations and RF spectra (shown in Fig. 9 and Fig. 10). Pulse duration in the mode-locked regime for $330 \mathrm{~mA}$ current is similar to $300 \mathrm{~mA}$ dynamics.

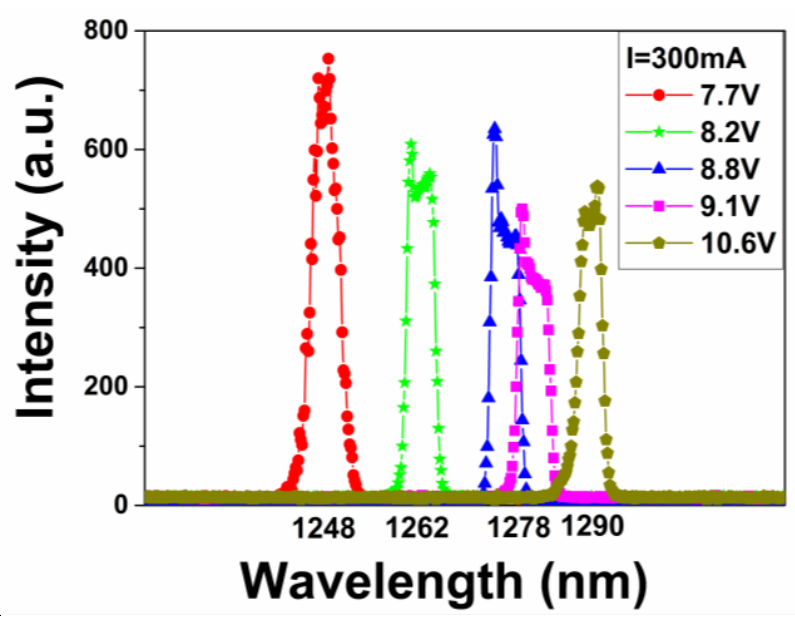

Fig. 8 Spectral tunability in the ascending direction with applied reverse bias for fixed gain current of $300 \mathrm{~mA}$ for wavelength tuning regime.
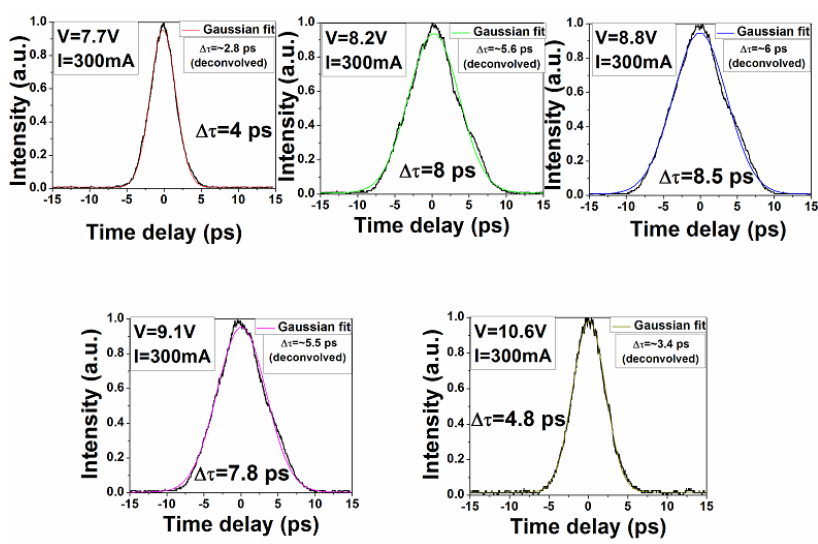

Fig. 9 Autocorrelation traces in the ascending direction with applied reverse bias for fixed gain current of $300 \mathrm{~mA}$ for wavelength tuning regime.

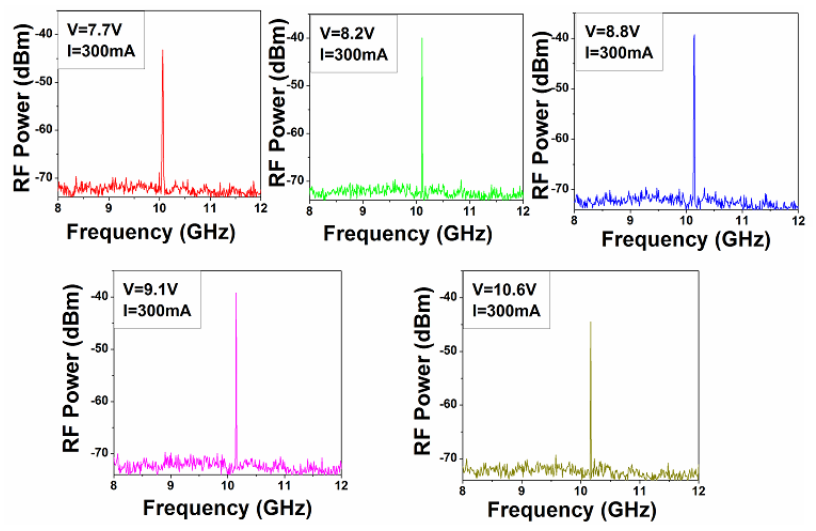

Fig. $10 \mathrm{RF}$ spectra in the ascending direction with applied reverse bias for fixed gain current of $300 \mathrm{~mA}$ for wavelength tuning regime.

The width of optical spectra is relatively independent of the applied reverse bias and changes from $4 \mathrm{~nm}$ to $5 \mathrm{~nm}$. As the result the TBWP decreases with applied voltages due to reduction of the pulse duration and varies from 2.5 to 4.8 for voltages above $4 \mathrm{~V}$. It means the pulses are still highly chirped. At the region of low reverse bias (less than $4 \mathrm{~V}$ ) the pulse width increases dramatically as the result TBWP values increases up to 18 .

\section{Discussion}

Two different regimes of mode-locking were observed in a two-section QD laser. Wavelength bistability was achieved when low (less than 6V) reverse bias was applied to the absorber section, while wavelength tunability in mode locking was observed for high (more than $6 \mathrm{~V}$ ) reverse bias regime.

The nonlinear absorption saturation along with electroabsorption induced by quantum confined Stark effect play major role in formation bistability [14]. 
When the absorber is under reverse bias at constant laser current the absorber current increases by the field at low reverse bias and reduces as absorption become more dominant [13].

While the tunability behavior of the laser in high reverse bias regime can potentially be attributed to increase of the absorption of the QD material, simultaneous spectral red shift due to quantum confined Stark effect [24, 25] in combination with a broad gain bandwidth achieved by employing non-identical QD layers [19]. Such changes would favor mode-locked operation towards increasingly longer wavelengths, within the available broadband gain.

Moreover, the wavelength tunability in mode-locked regime is achieved by only sweeping of the absorber without use of any optical components (gratings or mirrors) reducing the cost and complexity of the device. Thus a very promising swept laser source was developed which can be used in medical imaging applications such as optical coherence tomography due to minimum absorption and scattering in skin in that wavelength range [26]. The next step would be increasing the wavelength tuning range by changing the structure of the nonidentical capping layer. Further investigations are required to understand the physical mechanism underlying wavelength tunability.

\section{v. Conclusion}

In conclusion, we demonstrated highest switching range of $51.8 \mathrm{~nm}$ with picoseconds pulses in the range of $1245-1295 \mathrm{~nm}$. Moreover, a broad tunability range $(45 \mathrm{~nm})$ is also achieved from a monolithic mode-locked QD laser diode, with electronic control of the wavelength. Such versatility was enabled by the available broadband gain/absorption in QD lasers incorporating chirped QD layers. It is also important to stress that such wavelength is very important for telecommunication due to the minimum dispersion exhibited in that range.

\section{REFERENCES}

[1] G. J. Lasher, "Analysis of a proposed bistable injection laser, Solid-State Electronics, vol 7, pp. 707-716, 1964.

[2] H. Kawaguchi, "Bistable laser diodes and their applications: state of the art," IEEE J. Sel. Top. Quantum Electron. vol. 3, pp. 1254-1270, 1997.

[3] E. U. Rafailov, M. A. Cataluna, and W. Sibbett, "Mode-locked quantum-dot lasers," Nat. Photon., vol. 1, pp. 395-401, 2007.

[4] M. A. Cataluna, W. Sibbett, D. A. Livshits, J. Weimert, A. R. Kovsh, and E. U. Rafailov, "Stable mode locking via ground- or excited-state transitions in a two-section quantum-dot laser," Appl. Phys. Lett. vol. 89, pp. 081124-3, 2006.

[5] W. Zhou, O. Qasaimeh, J. Phillips, S. Krishna, P. Bhattacharya, "Bias-controlled wavelength switching in coupled-cavity In0.4Ga0.6As/GaAs self-organized quantum dot lasers“, Appl. Phys. Lett., vol. 74, pp.783-785, 1999.

[6] S. Breuer, M. Rossetti, W. Elsasser, L. Drzewietzki, P. Bardella, I. Montrosset, M. Krakowski, M. Hopkinson,"Reverseemission-state-transition mode locking of a two-section InAs/InGaAs quantum dot laser,"Appl. Phys. Lett. vol. 97, pp. 071118-3, 2010.

[7] M. A. Cataluna, D. I. Nikitichev, S. Mikroulis, H. Simos, C. Simos, C. Mesaritakis, D. Syvridis, I. Krestnikov, D. Livshits, and E. U. Rafailov, "Dual-wavelength mode-locked quantumdot laser, via ground and excited state transitions: experimental and theoretical investigation," Opt. Express, vol. 18, pp. 1283212838,2010

[8] M. S. Tahvili, L. Du, M. J. R. Heck, R. Notzel, M. K. Smit, and E. A. J. M. Bente, "Dual-wavelength passive and hybrid modelocking of 3, 4.5 and $10 \mathrm{GHz} \mathrm{InAs} / \mathrm{InP}$ (100) quantum dot lasers," Opt. Express, vol. 20, pp.8117-8135, 2012.

[9] C. Mesaritakis, C. Simos, H. Simos, I. Krestnikov, and D. Syvridis, "Dual ground-state pulse generation from a passively mode-locked InAs/InGaAs quantum dot laser," Appl. Phys. Lett. vol. 99, pp. 141109-3, 2011.

[10] E. Tangdiongga, Yang Xuelin, Li Zhonggui, Liu Yong, D. Lenstra, G. D. Khoe, and H. J. S. Dorren,"Optical flip-flop based on two-coupled mode-locked ring lasers," IEEE Phot. Tech. Lett. vol. 17, pp. 208-210, 2005.

[11] T. Yu, W. M. Reimer, V. S. Grigoryan, and C. R. Menyuk, "A Mean Field Approach for Simulating Wavelength-Division Multiplexed Systems," IEEE Phot. Tech. Lett. vol. 12, 443-445, 2000.

[12] Q. Fang, R. H. Moore, D. B. Kopans, D. A. Boas,"Compositional-prior-guided image reconstruction algorithm for multi-modality imaging," Biomed. Opt. Express vol. 1, pp. 223-235, 2010.

[13] O. Qasaimeh, W. D. Zhou, J. Phillips, S. Krishna, P. Bhattacharya, and M. Dutta, "Bistability and self-pulsation in quantum dot lasers with intracavity quantum dot saturable absorbers,” Appl. Phys. Lett. vol. 74, pp. 1654-1656, 1999.

[14] H. Xiaodong, A. Stintz, Li Hua, A. Rice, G. T. Liu, L. P. Lester, J. Cheng, and M. J. Malloy,"Bistable operation of a twosection $1.3 \mu \mathrm{m}$ InAs quantum dot laser-absorption saturation and the quantum confined Stark effect," IEEE J. Quantum Electron., vol. 37, pp. 414-417, 2001.

[15] H. Shoji, Y. Arakawa, and Y. Fujii,"Fast bistable wavelength switching characteristics in two-electrode distributed feedback laser," IEEE Phot. Tech. Lett. vol. 2, pp. 109-110, 1990.

[16] H. Zhang, V. Gauss, P. Wen, S. Esener, "Observation of wavelength and multiple bistabilities in $850 \mathrm{~nm}$ VerticalCavity Semiconductor Optical Amplifiers (VCSOAs)," Opt. Express vol. 15, pp. 11723-11730, 2007.

[17] M. Feng, N. A. Brilliant, S. T. Cundiff, R. P. Mirin, and K. L. Silverman, "Wavelength bistability in two-section mode-locked quantum-dot diode lasers," IEEE Phot. Tech. Lett. vol. 19, pp. 804-806, 2007.

[18] M. Feng, S. T. Cundiff, R. P. Mirin, and K. L. Silverman, "Wavelength bistability and switching in two-section quantumdot diode lasers," IEEE J. Quantum Electron. vol. 46, pp. 951958, 2010.

[19] K. A. Fedorova, M. A. Cataluna, I. Krestnikov, D. Livshits, and E. U. Rafailov, "Broadly-Tunable High-Power InAs/GaAs Quantum-Dot External-Cavity Diode Lasers," Opt. Express, vol. 18, pp. 19438-19443, 2010.

[20] B. J. Stevens, D. T. D. Childs, K. M. Groom, M. Hopkinson, and R. A. Hogg,"All semiconductor swept laser source utilizing quantum dots," Appl. Phys. Lett. vol. 91, pp. 121119-3, 2007.

[21] M.A. Cataluna, Y. Ding; D. Nikitichev, K. A. Fedorova, E. U. Rafailov, "High-Power Versatile Picosecond Pulse Generation 
from Mode-Locked Quantum-Dot Laser Diodes," Selected Topics in Quantum Electronics, IEEE Journal of , vol.17, no.5, pp.1302-1310, Sept.-Oct. 2011

[22] X. D. Huang, A. Stintz, H. Li,A. Rice, G. T. Liu, L. F. Lester, J. Cheng, and K. J. Malloy, "Bistable operation of a two-section 1.3- $\mu \mathrm{m}$ InAs quantum dot laser-Absorption saturation and the quantum confined Stark effect," IEEE J. Quantum Electron., vol. 37, no. 3, pp. 414-417, Mar. 2001

[23] D. B. Malins, A. Gomez-Iglesias, S. J. White, W. Sibbett, A. Miller, and E. U. Rafailov, "Ultrafast electroabsorption dynamics in an InAs quantum dot saturable absorber at 1.3 um," Appl. Phys. Lett., vol. 89, pp. 171 111-3, 2006.

[24] I. B. Akca, A. Dana, A. Aydinli, M. Rossetti, L. Li, A. Fiore, and N. Dagli,"Electro-Optic and Electro-absorption characterization of InAs quantum dot waveguides," Opt. Express 16, 3439-3444, 2008.

[25] L.M. Kong, Z. C. Feng, Z. Y. Wu, and W. Lu, "Emission dynamics of InAs self-assembled quantum dots with different cap layer structures" IOP Semicond. Sci. Technol. 23, 075044, 2008.

[26] W. Drexler, "Ultrahigh-resolution optical coherence tomography,” J.Biomed. Opt., vol. 9 (1), pp. 47-74, Jan. 2004.

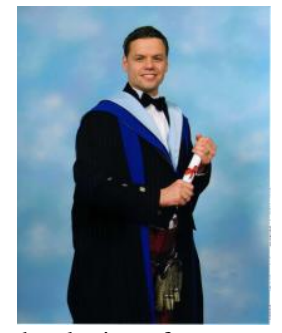

Daniil I. Nikitichev received Master degree in State University of the Information Technologies, Mechanics and Optics, Saint Petersburg, Russia, in 2008. He worked as an engineer at the Central Research Institute of Structural Materials "Prometey", doing research work in the area of Laser Thermo strengthening. He received a $\mathrm{PhD}$ degree at the University of Dundee in 2012, where he was working on the FAST-DOT project, developing of a new generation of compact and low cost ultrafast lasers based on quantum-dot materials. His current research interests include the development of high power tunable and bistable semiconductor devices and their application to multi-photon imaging techniques.

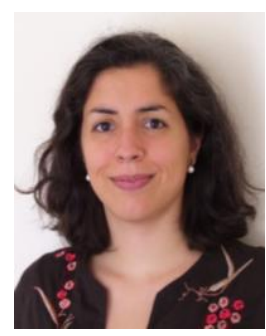

Maria Ana Cataluna was awarded the $\mathrm{Ph}$. D. in Laser Physics from the University of St Andrews, UK (2007). Since 2007 she has been with the University of Dundee, UK - firstly as a Research Fellow, and since 2009 as a Royal Academy of Engineering/EPSRC Research Fellow, having also been appointed as a Lecturer (2009-2012) and Senior Lecturer (since 2012). Dr Cataluna was a Work Package Leader in the European project FAST-DOT, which aimed to develop compact and low-cost ultrafast quantum-dot lasers for biophotonics (2008-2011). She has authored/co-authored more than 70 papers in peer-reviewed journals and conferences, several book chapters and one book. She was the recipient of an International $\mathrm{PhD}$ Studentship from Fundação para a Ciência e Technologia (Portugal) in 2003, the IEEE Photonics Society Graduate Student Fellowship in 2007, the Royal Academy of Engineering/EPSRC Research Fellowship in 2009 and the Philip Leverhulme Prize in 2011. She currently leads the Ultrafast Photonics Group at the University of Dundee. The Group's research is focused on the physics and technology of ultrafast photonic devices and related applications.

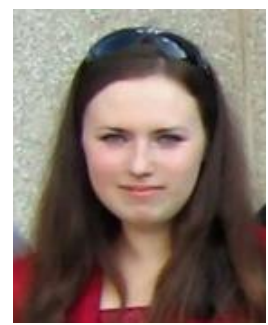

Ksenia A. Fedorova received the B.Sc. and M.Sc. degrees in Physics from the Nizhny Novgorod State University, Nizhny Novgorod, Russia, in 2005 and 2007, respectively, and obtained the Ph.D. in Electronic Engineering and Physics from the University of Dundee, Dundee, U.K. in 2011. She is currently a Marie Curie Research Fellow at the University of
Dundee in the Photonics and Nanoscience Group, where she is working on the study of novel quantum-dot materials for compact broadly tunable lasers and non-linear optics. Currently, her research interests also include the generation of the mid-IR radiation using novel quasiphase-matched semiconductor nonlinear crystals and wavelength conversion to the visible spectral range using periodically poled nonlinear crystals and quantum-dot edge-emitting laser diodes.

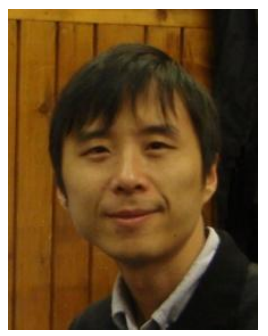

Ying Ding (M'11) received the Ph.D. degree in microelectronics and solid state electronics from the Institute of Semiconductors, Chinese Academy of Sciences, Beijing, China.

From 2005 to 2008, he was a Postdoctoral Researcher in the Research Center for Integrated Quantum Electronics, Hokkaido University, Hokkaido, Japan, where he was engaged in research on semiconductor nanowires. In 2008, he joined the Nanyang Technological University, Singapore, as a Research Fellow, where he was engaged in study on quantum-dot vertical-cavity surface-emitting lasers. He is currently a Senior Research Fellow at the University of Dundee, Dundee, U.K. His current research interests include quantumdot external-cavity mode-locked lasers and high-power integrated light sources with ultrashort pulse generation etc.

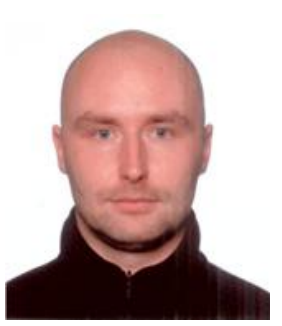

Sergey S. Mikhrin received his engineer degree from St.-Petersburg Electro-Technical University, Russia in 1999. In the same year he joined Molecular Beam Epitaxy group at A.F.Ioffe Physical-Technical Institute, St.Petersburg, Russia, where received his Ph.D. degree in physics in year 2002. In 2003 he joined Innolume $\mathrm{GmbH}$ as MBE engineer, specializing in growth of III-V semiconductor structures and in particular quantum-dot lasers.

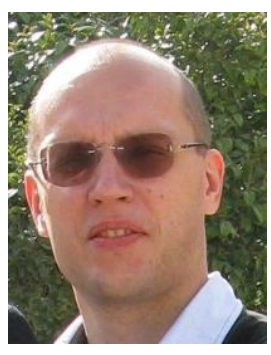

Igor L. Krestnikov joined Innolume in 2003 to lead several customer-based projects. Currently he focuses on development and production of quantum dot optoelectronic devices. Prior Innolume, Igor spent 3 years at the Technical University of Berlin as a Research Fellow. He received his PhD from Ioffe Physico-Technical Institute in St.Petersburg, Russia in 1998, doing his PhD research work in the group of Professor Alferov.

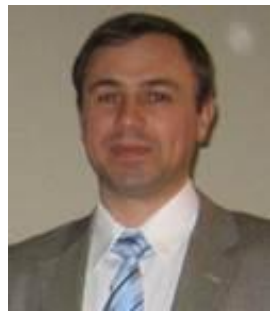

Daniil A. Livshits received the M.S. degree in physics in 1993 from the St. Petersburg State Technical University He joined Ioffe institute of Physics and Technology in 1991 for R\&D of high power laser diodes and VCSELs. He got his Ph.D. degree in physics in 2000 from the same institute. During 20012003 as visiting scientist was developing InGaAsN lasers and VCSELs in the Industrial Technology Research Institute in Taiwan and in 2004 joined the newborn startup in Germany - Innolume GmbH which was growing from one MBE machine company to fully integrated fab with tens of unique products based on quantum dots. Daniil was one of the main driving forces to establish the fab, technology, qualified production and business development of the company. Since 2010 he is serving as CTO at Innolume. 


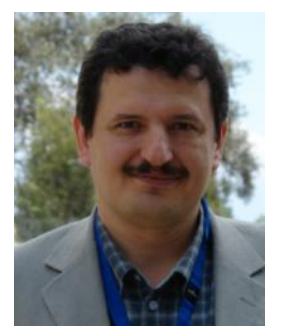

Edik U. Rafailov received the Ph.D. degrees from the Ioffe Institute, St Petersburg in 13.01.1992. In 1997 he moved from St Petersburg to St Andrews University as a Research Fellow and in 2005 he moved to Dundee University as a lecturer and established new Photonics and Nanoscience group. In 2008 he became a Reader and in 2010 Professor. He has authored and co-authored over 200 articles in refereed journals and conference proceedings, including one book, three invited chapters and numerous invited talks to CLEO, SPIE and LEOS. He also holds 8 UK and two US patents. Prof. Rafailov coordinates a €13.7M FP7 European IP project (FAST-DOT) intended to develop new miniature low-cost ultrafast lasers based on quantum-dot materials for applications in biophotonics and cellular-surgery. He also leads a few others projects funded by FP7

EU and EPSRC. His current research interests include novel high-power $\mathrm{CW}$, short, ultrashort-pulse and high-repetition rate lasers; generation of $\mathrm{UV} /$ visible/IR/MIR and THz radiation, nano-structures; nonlinear and integrated optics; biophotonics. 